\title{
New Insights in Mixed Vitiligo: Initial Non Segmental Vitiligo can precede the Onset of Segmental Vitiligo (Cases Report and Review of Theories)
}

\author{
Benzekri $\mathrm{L}^{1^{*}}$ and Gauthier $\mathrm{Y}^{2}$ \\ ${ }^{1}$ Mohammed V Souissi University Rabat, Department of Dermatology, Ibn Sina University Hospital, Rabat, Morocco \\ ${ }^{2}$ Technical Advisor of French Vitiligo Association, France
}

*Corresponding author: Laila Benzekri, Res. Nassim Riad, Av. Mehdi Ben Barka, Im.3, n6, Hay Riad, Sect. 8, 10100 Rabat, Morocco, Tel:+212-67-1964-111; E-mail: benzekrilaila@yahoo.fr

Rec date: May 19, 2014; Acc date: June 25, 2014; Pub date: June 27, 2014

Copyright: (c) 2014 Benzekri L, This is an open-access article distributed under the terms of the Creative Commons Attribution License, which permits unrestricted use, distribution, and reproduction in any medium, provided the original author and source are credited.

\begin{abstract}
Recently, mixed vitiligo (MV) was defined by Mulekar as the association of segmental vitiligo (SV) and nonsegmental vitiligo (NSV) in the same patient. Until now, SV and generalized NSV were considered to be separate entities with a different distribution (unilateral or bilateral). Generalized vitiligo seemed to be more frequently associated with other autoimmune diseases than SV. From the pathophysiological standpoint, it was hypothesized that NSV was an autoimmune disease, while SV may result of a sympathetic dysfunction. The first pediatric case of SV associated with NSV was reported in 2003 and 36 other observations were subsequently reported. In all these cases, segmental involvement associated usually in a second step with the onset of bilateral vitiligo patches. In this article, we describe, for the first time, two atypical cases of mixed vitiligo in which NSV involvement preceded the onset of SV. In the light of these remarkable cases, different possible aetiopathogenetic mechanisms of MV are discussed which may provide new insights into the pathogenesis of vitiligo.
\end{abstract}

Keywords: Mixed vitiligo; Segmental vitiligo; Generalized vitiligo; Mosaicism; Vitiligo pathogenesis

\section{Introduction}

Until the publication of the first case of Mixed Vitiligo (MV), SV and NSV were considered for many years as separate entities with no evident links between them except the loss of melanocytes. The recently demonstrated association of SV and NSV has provided new insights in the pathogenesis of vitiligo. Actually these two subtypes could be considered as variants of a same disease spectrum.

\section{SV and NSV as separate entities}

Clinically, SV is characterized by a unilateral distribution, an early onset, a rapid extension in a presupposed dermatome, a frequent involvement of hair follicle compartment and a non-significant association with other autoimmune disease. At the opposite, NSV is an acquired chronic pigmentary disorder characterized by a bilateral and often symmetrical distribution of the white patches, an unpredictable course, a polymorphous aspect of the lesions, a significant association with autoimmune diseases and a frequent family history [1-3].

At the histological level, the biopsy at the margin of established macules of SV shows apparently normal skin except for the absence of pigmentation of the epidermal layer. Nevertheless, it was reported in some cases of SV, inflammatory and lichenoid infiltrate of the epidermis and of the dermis [4]. In contrast, in active lesions of NSV with poorly defined borders and hypomelanotic aspect, CD8Tlymphocytes were found close epidermal melanocytes within microvesicles [5].

From the pathophysiological standpoint, Koga have reported a decreased responsiveness of sweat secretion stimulated by physostigmine in SV [6]. Moreover, a significant increase in cutaneous alpha and beta adrenoreceptor was found in SV skin [7]. These findings not reported in NSV skin suggested a dysfunction of the sympathetic nerves in SV.

Different aetiopathogenetic mechanisms leading to clear differences in disease presentation, evolution and associated disease were successively proposed.

In SV, the neural/neurogenic theory supported by clinical, ultrastructural and biochemical arguments was reported $[8,9]$. However data are discordant and the role of nervous system is probable but poorly established. More recently, it has been suggested that SV might follow Blashko's lines and could be considered as the possible expression of cutaneous mosaicism [10,11]. SV would be probably more informative in terms of skin causative genes because associated autoimmune disorders are rare in SV [12].

NSV could be considered as a multifactorial and polygenic disease involving multiple genes and non-genetic factors. According to the "melanocytorrhagy hypothesis", melanocytes of genetically susceptible individuals might be subjected to detachment and consequent cell death following mechanical traumas due to a defect of E-cadherin recently objectivated [13-16]. Among the numerous environmental factors implicated in the melanocyte loss, immune process has certainly a key role in the pathogenesis of NSV through cell-mediated immunity and also humoral immunity [17-20]. Moreover, the frequent association of NSV with autoimmune disease could lead to consider it as a systemic disease [21]. It is most likely that the loss of melanocytes in NSV arises through a combination of pathogenic mechanisms that act in concert [22]. Alternative mechanisms of melanocyte damage such as cell detachment, biochemical or oxidant damage, autocytotoxicity, neurocytotoxicity could induce the release of heat shock protein and enhance the antigen presentation and immune activation [23-28]. Genes certainly play a role in all aspect of 
NSV pathogenesis. But we do not know how many major genes may be involved in NSV and in what different combinations. Actually only genes associated with autoimmune susceptibility such as HLA, PTPN22, NALP1 and CTL4 have been identified with reasonable certainty [29,30]. Many other candidate genes have been suggested and studied for NSV which were involved in melanocyte development, cell adhesion and transportation of melanosomes [31].

\section{SV and NSV as variants of the same disease spectrum}

Recent theories suggested that SV is not a complete separate entity but has a clear overlap with NSV at the clinical, genetical and aetiopathological level [32]. The presence of halo nevi seems nearly as frequent in SV and in NSV and could be considered as a shared "immune phenotype". It has been hypothesized that progression from SV to MV would be correlated to a secondary immune response directed against melanocytes at distance from the initial SV [33]. Halo nevi and leukotrichia frequently observed during the evolution of SV to MV could be considered as strong predictors [34]. This sequence early SV/ late NSV may likely reflect the role of cutaneous gene defect causing SV and further inducing a generalized immune response. A new pathogenic model was proposed to explain the association of SV to NSV. In several common acquired skin disorders with polygenic background, a segmental arrangement may sometimes be observed [35]. The segmental involvement could be explained by the concept of Loss of Heterozygoty $(\mathrm{LOH})$. $\mathrm{LOH}$ is a genetic mechanism which may result from various mutational mechanisms. In polygenic skin disorders the descriptive term of "superimposed segmental manifestation" was proposed to categorize this anomaly [36]. It was hypothesized that an early mutation in heterozygous embryo occurring to a stem cell of a clone could give rise firstly to segmental component of MV during childhood and then later in life to classical patches of NSV. Moreover the concept of early loss of heterozygoty could give a possible explanation as to why in some cases family members may show the disorders in its non-segmental form. Finally the existence of a mixed type pattern could suggest a "continuum" between SV and NSV [32,34].

\section{Cases of Mixed Vitiligo Previously Published}

Since the first report of a pediatric case in 2003 [13], 36 cases of Mixed Vitiligo [MV], characterized by the association of segmental and non-segmental vitiligo in the same patient, have been successively published [37-39]. In a recent study of 762 vitiligo patients, MV was observed in $0.4 \%$ of cases $[40,41]$. This phenomenon may have been neglected previously due to NSV masking SV. MV was included recently in the classification of vitiligo besides SV and NSV [1]. In all the previously reported cases, segmental vitiligo always preceded non segmental vitiligo, with a delay ranging from six months to more than 24 months. According to the age of the recruited patients in the study, the importance of other parameters was variably related to occurrence of Koebner's phenomenon, halo nevi and leukotrichia, or association with autoimmune diseases [33].

\section{Cases Report}

In this study, we report, for the first time, two atypical cases of mixed vitiligo

- $\quad$ Case 1: A 56 year-old female suffered for 20 years from slowly extensive non segmental vitiligo affecting the trunk, upper and lower limbs, and extremities. Recently, a large segmental vitiligo located on the left lombo-abdominal area appeared following a cholecystectomy (Figure 1). Koebner's phenomenon was observed on the surgical scar, but halo nevi and leukotrichia were not found. Thyroid function was not investigated. No treatment was planned (Table 1).

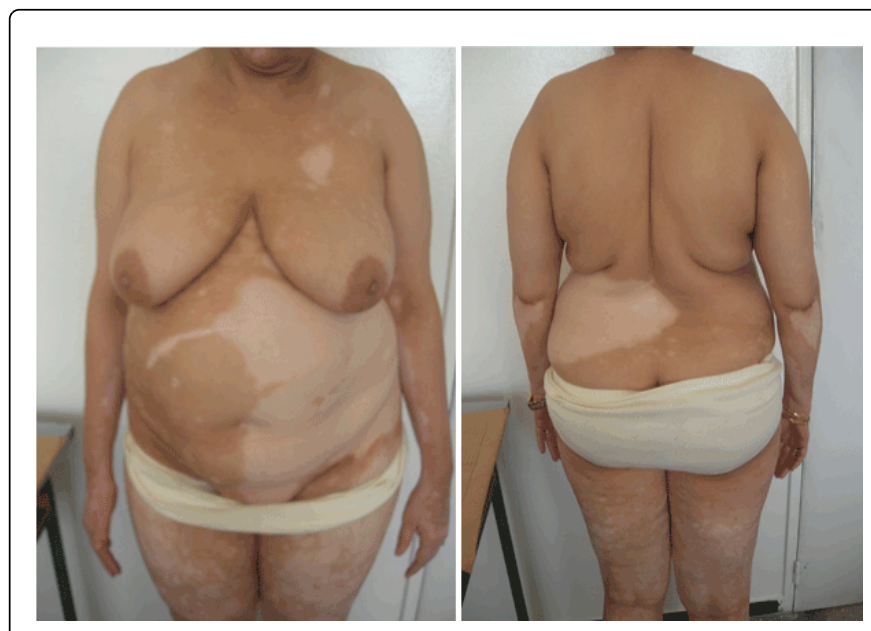

Figure 1: Mixed vitiligo (case ${ }^{\circ} 1$ ) A: Preexisting NSV located on upper limbs, lower limbs and thorax associated with large SV on left flank. Evident Koebner's phenomenon developed on surgical scar (on right side).

B: Preexisting NSV of the upper and lower limbs associated with SV developed on the lumbar area (on left side)

- Case 2: A 21 year-old female, with a family history of vitiligo, presented non-segmental vitiligo for five years localized on the back, the breast, the face and the lower limbs. Four years after the onset of the initial lesions, new depigmented lesions developed, strictly located on the right buttock and flank in a segmental fashion. Leukotrichia was found in the skin affected by segmental vitiligo, and Koebner's phenomenon was objectivated in the normal surrounding skin. Halo nevi were not observed. Histological study of the margin of SV did not show any inflammatory infiltrate in the dermis and the epidermis. A thyroid checkup was normal. Scoliosis topographically compatible with the segmental vitiligo lesions was found. The non-segmental vitiligo lesions repigmented more easily under phototherapy than the segmental vitiligo lesions. (Table 1)

\begin{tabular}{|l|l|l|l|l|l|l|}
\hline Patient & $\begin{array}{l}\text { Delay } \\
\text { between } \\
\text { initial NSV } \\
\text { and onset of } \\
\text { SV }\end{array}$ & $\begin{array}{l}\text { Koebner's } \\
\text { phenomen } \\
\text { on }\end{array}$ & Halo nevi & $\begin{array}{l}\text { Poliosi } \\
\text { s }\end{array}$ & $\begin{array}{l}\text { Thyroid } \\
\text { Check- } \\
\text { up }\end{array}$ & $\begin{array}{l}\text { Family } \\
\text { history }\end{array}$ \\
\hline $\begin{array}{l}\text { Case } \mathrm{n} \\
{ }^{1}\end{array}$ & 20 years & yes & no & no & $\begin{array}{l}\text { not } \\
\text { done }\end{array}$ & unknown \\
\hline $\begin{array}{l}\text { Case } \mathrm{n} \\
{ }^{\circ} 2\end{array}$ & 4 years & yes & no & yes & normal & yes \\
\hline
\end{tabular}

Table 1: Clinical features in 2 patients in which initial NSV have preceded the onset of SV

\section{Discussion}

We herein reported a case series of two patients with the diagnosis of atypical MV collected in a period of 8 years. In our case series, the initial type of vitiligo which was observed was the non-segmental 
vitiligo type and not the segmental type as in previous studies. The later age of onset of SV in this series (56 years in case 1, 21 years in case 2) is not in keeping with previous observations. The delay between the two clinical manifestations was longer, ranging from 4 years (case 2) to 20 years (case 1). Consistently, the segmental dermatomal involvement of the trunk predominated, leukotrichia in SV was found (case 2), Koebner's phenomenon was observed in the two cases, scoliosis was detected in case 2 and NSV responded well to narrowband UVB phototherapy whereas SV responded poorly (case 2).

It is not always easy to distinguish the onset of new SV lesions from preexisting NSV lesions developed on the skin; consequently SV could be often misdiagnosed.

If the concept of superimposed segmental manifestation of polygenic skin disorders seems plausible to give a reasonable explanation for the majority of cases of MV until now reported, it is not the case for our two atypical cases. The proposed concept of superimposed segmental vitiligo remains still a theory and demonstrative data at the molecular level are still missing. Can we consider these cases as exceptions or as other types of combination between NSV and SV? In fact the hypothesis of cutaneous mosaicism does not rule out other triggering factors such as neurogenic factors. A convergent "three step theory" including several pathomechanisms such as elevation of neuropeptides and activation of melanocytespecific T-cells was recently proposed for the SV [32]. So we suggest that the later onset of SV in our atypical cases could be considered as the consequence of a Koebner's phenomenon induced in caselby surgical treatment and perhaps in case 2 by the scoliotic anomaly. Whatever the different clinical sequences described, the interesting link existing between NSV and SV still remains enigmatic and further investigations at the molecular level are needed.

\section{Conclusion}

The association of SV and NSV will provide certainly new insights in the pathogenesis of vitiligo disease. We underline that, in a few cases, non-segmental vitiligo can be an early event in the genesis of mixed vitiligo.

\section{References}

1. Ezzedine K, Lim HW, Suzuki T, Katayama I, Hamzavi I, et al. (2012) Revised classification/nomenclature of vitiligo and related issues: the Vitiligo Global Issues Consensus Conference. Pigment Cell Melanoma Res 25: E1-13.

2. Gauthier Y, Benzekri L, Hann SK (2010) Segmental vitiligo : epidemiology and clinical features:Vitiligo Springer Heidelberg,Dordrecht,London, New York p42-3.

3. van Geel N, De Lille S, Vandenhaute S, Gauthier Y, Mollet I, et al. (2011) Different phenotypes of segmental vitiligo based on a clinical observational study. J Eur Acad Dermatol Venereol 25: 673-678.

4. Attili VR, Attili SK (2013) Segmental and generalized vitiligo: both forms demonstrate inflammatory histopathological features and clinical mosaicism. Indian J Dermatol 258: 433-438.

5. Benzekri L, Gauthier Y, Hamada S, Hassam B (2013) Clinical features and histological findings are potential indicators of activity in lesions of common vitiligo. Br J Dermatol 168: 265-271.

6. Koga M, Tango T (1988) Clinical features and course of type A and type B vitiligo. Br J Dermatol 118: 223-228.

7. Koga M, Tango T (1988) Clinical features and course of type A and type B vitiligo. Br J Dermatol 118: 223-228.
8. Wu CS, Yu HS, Chang HR, Yu CL, Yu CL, et al. (2000) Cutaneous blood flow and adrenoceptor response increase in segmental-type vitiligo lesions. J Dermatol Sci 23: 53-62.

9. Al'Abadie MS, Senior HJ, Bleehen SS, Gawkrodger DJ (1994) Neuropeptide and neuronal marker studies in vitiligo. Br J Dermatol 131: 160-165.

10. Gauthier Y, Benzekri L (2010) The neurogenic hypothesis in segmental vitiligo. Vitiligo Springer Heidelberg,Dordrecht,London, New York.

11. Taïeb A, Morice-Picard F, Jouary T, Ezzedine K, Cario-André M, et al. (2008) Segmental vitiligo as the possible expression of cutaneous somatic mosaicism: implications for common non-segmental vitiligo. Pigment Cell Melanoma Res 21: 646-652.

12. van Geel N, Speeckaert R, Melsens E, Toelle SP, Speeckaert M, et al. (2013) The distribution pattern of segmental vitiligo: clues for somatic mosaicism. Br J Dermatol 168: 56-64.

13. Hann SK Taieb A, Gauthier Y, Benzekri L, et al. (2010) Segmental vitiligo : A model to understand vitiligo : Vitiligo Springer Heidelberg,Dordrecht,London, New York.

14. Gauthier Y, Cario Andre M, Taïeb A (2003) A critical appraisal of vitiligo etiologic theories. Is melanocyte loss a melanocytorrhagy? Pigment Cell Res 16: 322-332.

15. Kim NH, Lee AY (2010) Reduced aquaporin 3 expression and survival of keratinocytes in the depigmented epidermis of vitiligo. J Invest Dermatol 130: 2231-2239.

16. Delmas V,Rubod A,Luciani F, et al. (2012) E-cadherin is required for melanocyte maintenance in the basal layer and is altered in vitiligo melanocytes. J Invest Dermatol 132:S44-49.

17. Cario-André M, Pain C, Gauthier Y, Taïeb A (2007) The melanocytorrhagic hypothesis of vitiligo tested on pigmented, stressed, reconstructed epidermis. Pigment Cell Res 20: 385-393.

18. Ongenae K, Van Geel N, Naeyaert JM (2003) Evidence for an autoimmune pathogenesis of vitiligo. Pigment Cell Res 16: 90-100.

19. Le Poole IC, Luiten RM (2008) Autoimmune etiology of generalized vitiligo. Curr Dir Autoimmun 10: 227-243.

20. Malhotra N, Dytoc M (2013) The pathogenesis of vitiligo. J Cutan Med Surg 17: 153-172.

21. van den Wijngaard R, Wankowicz-Kalinska A, Le Poole C, Tigges B, Westerhof W, et al. (2000) Local immune response in skin of generalized vitiligo patients. Destruction of melanocytes is associated with the prominent presence of CLA+ T cells at the perilesional site. Lab Invest 80: $1299-1309$

22. Lotti T, D'Erme AM (2014) Vitiligo as a systemic disease. Clin Dermatol 32: $430-434$.

23. Namazi MR (2007) Neurogenic dysregulation, oxidative stress, autoimmunity, and melanocytorrhagy in vitiligo: can they be interconnected? Pigment Cell Res 20: 360-363.

24. Boissy RE, Manga P (2004) On the etiology of contact/occupational vitiligo. Pigment Cell Res 17: 208-214.

25. Morrone A, Picardo M, de Luca C, Terminali O, Passi S, et al. (1992) Catecholamines and vitiligo. Pigment Cell Res 5: 65-69.

26. Schallreuter KU, Moore J, Wood JM, Beazley WD, Gaze DC, et al. (1999) In vivo and in vitro evidence for hydrogen peroxide $(\mathrm{H} 2 \mathrm{O} 2)$ accumulation in the epidermis of patients with vitiligo and its successful removal by a UVB-activated pseudocatalase. J Investig Dermatol Symp Proc 4: 91-96.

27. Laddha NC, Dwivedi M, Mansuri MS, Gani AR, Ansarullah M, et al. (2013) Vitiligo: interplay between oxidative stress and immune system. Exp Dermatol 22: 245-250.

28. Dell'anna ML, Picardo M (2006) A review and a new hypothesis for nonimmunological pathogenetic mechanisms in vitiligo. Pigment Cell Res 19: 406-411.

29. Le Poole IC, Norris D (2010) Cell mediated immunity: Vitiligo Springer, Heidelberg, Dordrecht, London, New York.

30. Spritz RA (2007) The genetics of generalized vitiligo and associated autoimmune diseases. Pigment Cell Res 20: 271-278. 
Citation: Benzekri L, Gauthier Y (2014) New Insights in Mixed Vitiligo: Initial Non Segmental Vitiligo can precede the Onset of Segmental Vitiligo (Cases Report and Review of Theories). Pigmentary Disorders 1: 114. doi:10.4172/jpd.1000114

Page 4 of 4

31. Boissy RE, Spritz RA (2009) Frontiers and controversies in the pathobiology of vitiligo: separating the wheat from the chaff. Exp Dermatol 18: 583-585.

32. Strömberg S, Björklund MG, Asplund A, Rimini R, Lundeberg J, et al. (2008) Transcriptional profiling of melanocytes from patients with vitiligo vulgaris. Pigment Cell Melanoma Res 21: 162-171.

33. van Geel N, Mollet I, Brochez L, Dutré M, De Schepper S, et al. (2012) New insights in segmental vitiligo: case report and review of theories. Br J Dermatol 166: 240-246.

34. Ezzedine K, Diallo A, Léauté-Labrèze C, Séneschal J, Prey S, et al. (2012) Halo naevi and leukotrichia are strong predictors of the passage to mixed vitiligo in a subgroup of segmental vitiligo. Br J Dermatol 166: 539-544.

35. Taieb A (2010). The concept of mosaicism applied to segmental vitiligo: Vitiligo Springer, Heidelberg, Dordrecht, London, New York pp 298-302
36. Happle R (1999) Loss of heterozygosity in human skin. J Am Acad Dermatol 41: 143-164.

37. Happle R (2007) Superimposed segmental manifestation of polygenic skin disorders. J Am Acad Dermatol 57: 690-699.

38. Mulekar SV, Al Issa A, Asaad M, Ghwish B, Al Eisa A (2006) Mixed vitiligo. J Cutan Med Surg 10: 104-107.

39. Ezzedine K, Gauthier Y, Léauté-Labrèze C, Marquez S, Bouchtnei S, et al. (2011) Segmental vitiligo associated with generalized vitiligo (mixed vitiligo): a retrospective case series of 19 patients. J Am Acad Dermatol 65: 965-971.

40. Neri I, Russo T, Piccolo V, Patrizi A (2013) Mixed vitiligo in childhood: a study on 13 Italian patients. J Eur Acad Dermatol Venereol 27: e140-141.

41. Agarwal S, Ojha A, Gupta S (2014) Profile of vitiligo in kumaun region of uttarakhand, India. Indian J Dermatol 59: 209. 